\title{
StatSensor-i point-of-care creatinine analyzer may identify patients at high-risk of contrast-induced nephropathy
}

\author{
AKITOSHI INOUE ${ }^{1,2}$, NORIHISA NITTA ${ }^{1}$, SHINICHI OHTA ${ }^{1}$, KATSUJI IMOTO $^{2}$, \\ MICHIO YAMASAKI ${ }^{2}$, MITSURU IKEDA ${ }^{3}$ and KIYOSHI MURATA ${ }^{1}$ \\ ${ }^{1}$ Department of Radiology, Shiga University of Medical Science, Seta-Tsukinowa-cho, Otsu, Shiga 520-2192; \\ ${ }^{2}$ Department of Radiology, Kohka Public Hospital, Koka, Shiga 528-0074; ${ }^{3}$ Division of Radiological Technology, \\ School of Health Sciences Radiological Technology, Nagoya University, Higashi, Nagoya, Aichi 461-0047, Japan
}

Received May 13, 2016; Accepted March 3, 2017

DOI: $10.3892 /$ etm.2017.4389

\begin{abstract}
The current study assessed the accuracy of the StatSensor-i (STA) point-of-care creatinine analyzer prior to and following adjustment (offset correction) by linear regression scatter plots produced by the reference samples from patients and volunteers for detecting high risk of contrast-induced nephropathy in patients with an estimated glomerular filtration rate $<45 \mathrm{ml} / \mathrm{min} / 1.73 \mathrm{~m}^{2}$. Blood samples were obtained from 233 consecutive outpatients scheduled for contrast-enhanced CT studies. Of the 233 patients, 123 patient samples were evaluated prior to adjustment and the other 110 following adjustment. Serum creatinine levels and estimated glomerular filtration rate were measured using the analyzer and compared with the values returned by laboratory tests. Analysis was with the paired t-test, the Pearson correlation coefficient and Bland-Altman plotting. The sensitivity, specificity, positive and negative predictive values (PPV, NPV), and accuracy for detecting patients with an estimated glomerular filtration rate $<45 \mathrm{ml} / \mathrm{min} / 1.73 \mathrm{~m}^{2}$ were subsequently calculated. Mean serum creatinine levels measured with the analyzer were significantly higher than those returned by laboratory tests before $(\mathrm{P}<0.0001)$ and after adjustment $(\mathrm{P}<0.01)$. Following adjustment, the difference in serum creatinine values obtained with the STA analyzer and by laboratory methods did not exceed $0.3 \mathrm{mg} / \mathrm{dl}$. Prior to adjustment, $9.7 \%$ of the samples were overdiagnosed as having an estimated glomerular filtration rate of $<45 \mathrm{ml} / \mathrm{min} / 1.73 \mathrm{~m}^{2}$; following adjustment, the overdiagnosis rate was $2.7 \%$. The sensitivity, specificity, PPV, NPV and accuracy were 100, 89, 50, 100 and $90.2 \%$ before and 100, 96.3, 33.3, 100 and $96.4 \%$
\end{abstract}

Correspondence to: Dr Akitoshi Inoue, Department of Radiology, Shiga University of Medical Science, Seta-Tsukinowa-cho, Otsu, Shiga 520-2192, Japan

E-mail: akino@belle.shiga-med.ac.jp

Key words: iodine contrast media, contrast-induced nephropathy, point-of-care, serum creatinine value, estimated glomerular filtration rate after adjustment, respectively. With the adjusted point-of-care creatinine analyzer, estimated glomerular filtration rate may be reliably evaluated in the radiology suite.

\section{Introduction}

Iodine contrast media (ICM) and gadolinium-based contrast agents (GBCA) are essential for diagnostic imaging studies performed to depict the vascular anatomy or to evaluate the blood flow following computed tomography (CT) and magnetic resonance imaging (MRI) studies, respectively. Contrast-induced nephropathy (CIN) is a major and common side effect of ICM use and nephrogenic systemic fibrosis (NSF) is a severe side effect of using $\operatorname{GBCA}(1,2)$.

CIN is defined as an absolute increase in serum creatinine ( $\mathrm{sCr}$ ) level of $\geq 0.3 \mathrm{mg} / \mathrm{dl}$, a percentage increase in $\mathrm{sCr}$ of $\geq 50 \%$, or a reduction in urine output (oliguria of $<0.5 \mathrm{ml} / \mathrm{kg} / \mathrm{h}$ for $>6 \mathrm{~h}$ ) within $48 \mathrm{~h}$ (1). The incidence of CIN following contrast-enhanced (CE)-CT has been reported as $2-12 \%$ (3). For some patients, CIN may result in the onset of severe renal failure, the need for dialysis, and increased length of hospitalization (3). In patients with severe renal failure, early renal replacement therapy may decrease mortality and the incidence of complications (4).

The symptoms of NSF include skin discoloration, swelling and pain (2). Some patients suffering from reduced joint movement due to skin thickening are forced to use a wheelchair (2). Determining the true incidence of NSF is difficult; however, 1,600 cases were reported to the US Food and Drug Administration in 2012 (5). Symptomatic treatment with intensive physiotherapy and painkillers is important, however there is currently no specific treatment for NSF (6).

One proposed mechanism of CIN is that interactions of iodine and amino acids damage cell membranes, causing a direct toxic effect on renal tubular and vascular cells (7). Pre-existing chronic kidney disease is considered an independent risk of CIN (8). The pathogenesis of NSF is the slow excretion of GBCA in patients with severe renal impairment (2). Therefore, patients with a glomerular filtration rate (GFR) $<45 \mathrm{ml} / \mathrm{min} / 1.73 \mathrm{~m}^{2}$ have a high risk of developing CIN and a GFR $<30 \mathrm{ml} / \mathrm{min} / 1.73 \mathrm{~m}^{2}$ also puts patients at high risk for NSF $(1,2)$. The estimated glomerular filtration rate (eGFR), 
calculated based on patient sex and age and the ( $\mathrm{sCr}$ ) level, is used in place of the GFR by the majority of institutions and used prior to CE-CT and MRI studies to identify patients at high risk of developing CIN and NSF. Outpatients with no recent eGFR data must wait for the $\mathrm{sCr}$ value to be returned by laboratory tests prior to undergoing CE-CT or CE-MRI, although in urgent situations, such as patients with suspected strangulated small bowel obstruction which requires the assessment of blood flow by CE-CT, renal function must be determined immediately (1-3).

The StatSensor-i (STA; Nova Biomedical, Waltham, MA, USA), a rapid, hand-held, commercially available point-of-care creatinine analyzer (Fig. 1), measures the $\mathrm{sCr}$ levels in blood samples in $30 \mathrm{sec}$. It is used to screen for chronic kidney disease (CKD) (9), adjusting doses of potentially toxic renal drugs whose administration requires renal function monitoring (10) and to monitor kidney transplant recipients (11). The instrument is also used for evaluating renal function in radiology suites (12-14). To manage the risk of CIN, the accuracy of eGFR values between 30 and $45 \mathrm{ml} / \mathrm{min} / 1.73 \mathrm{~m}^{2}$ is particularly important. The correlation of $\mathrm{sCr}$ and eGFR determined by laboratory tests and STA is currently unclear, although previous studies have reported an underestimation in $\mathrm{sCr}$ without offset collection (14).

The present study assessed the accuracy of the STA analyzer in the detection of patients with a high risk for CIN (eGFR $<45 \mathrm{ml} / \mathrm{min} / 1.73 \mathrm{~m}^{2}$ ) by comparing the values obtained prior to and following adjustment (offset correction) by linear regression scatter plots produced by the reference samples from patients and volunteers.

\section{Patients and methods}

Patients. The present retrospective study was approved by the institutional review board of Kohka Public Hospital Review Board (\#334; Shiga, Japan). The requirement for informed consent was waived and the patient records and information were anonymized prior to analysis. The pre-adjustment study included 123 consecutive outpatients (74 males, 49 females, mean age $66.7 \pm 12.5$ years) who underwent CE-CT at Kohka Public Hospital (Koka, Japan) between September 2011 and February 2012. The sCr level of the patients had not been assessed in the month preceding hospital admittance. In the post-adjustment study, 110 consecutive outpatients (62 males, 48 females, mean age 70.1 12.7 years) who underwent CE-CT at Kohka Public Hospital between June and November 2012, were enrolled. There were no exclusion criteria in this study.

Samples. All blood samples were taken in the radiology suite. Prior to CT, peripheral blood samples were obtained by fingertip puncture with a 28-gauge needle (LS Lancet; Nipro Corporation, Osaka, Japan) and assessed with the point-of-care STA analyzer. Cubital vein blood samples obtained with a 20- or a 22-gauge needle (Supercath; Medikit Co., Ltd., Tokyo, Japan) were collected into a blood-collecting vessel containing a blood coagulation accelerant, thrombin (Neotube; Nipro Corporation, Osaka, Japan). The venous samples were analyzed in the laboratory with a creatinine kit (L-type Wako CRE EM; Wako Pure Chemical Industries, Ltd., Osaka, Japan) that applies the enzymatic method in an automatic analyzer
(BioMajesty ${ }^{\mathrm{TM}}$ JCA-BM2250; JEOL Ltd., Tokyo, Japan). The eGFR was calculated using a converting equation, as follows: $\mathrm{eGFR}=194 \mathrm{x}(\mathrm{sCr})^{-1.094} \mathrm{x}(\mathrm{age})^{-0.287} \mathrm{x}(-0.739$ for females $)$ published by the Japanese Society of Nephrology-Chronic Kidney Disease Initiatives (15). It is necessary to multiply the coefficient $(0.739)$ for females because muscle mass and creatinine values are lower in females than in males.

Adjustment of the STA analyzer. A total of 3 healthy male volunteers (mean age: 41.1 \pm 9.0 years) were recruited at Kohka Public Hospital to serve as a control group. All volunteers gave prior informed consent and venous blood samples were collected into the blood-collecting vessel containing thrombin. In the volunteer samples, $\mathrm{sCr}$ was measured with the STA and the BM2250 analyzer, which adds $1.0 \mathrm{mg} / \mathrm{dl}$ of a creatinine spiking solution (Sigma-Aldrich; Merck KGaA, Darmstadt, Germany) to obtain samples with a creatinine concentration of 2.0-3.0 mg/dl. The volunteer data are presented in Fig. 2 (Fig 2B). For adjustment, linear regression scatter plots were produced for the other 69 samples from patients (40 males, 29 females, mean age 67.2 \pm 12.9 years) who underwent CE-CT in the department of radiology in Kohka Public Hospital admitted between March and May 2012, and for samples from the three volunteers that were assayed with the STA and the BM2500 analyzer. Samples that returned sCr values between 0 and $2.0(n=68)$, and 0 and $3.0 \mathrm{mg} / \mathrm{dl}(\mathrm{n}=102)$ were used to adjust the values obtained with the STA analyzer.

On scatter plots with linear regression from $\mathrm{sCr}<2.0$ the values measured with the STA and the BM2250 analyzer exhibited a significant correlation $(\mathrm{r}=0.830, \mathrm{y}=1.105 \mathrm{x}+0.080$; $\mathrm{P}<0.0001$; Fig. 1A). The correlation for samples with $\mathrm{sCr}$ $<3.0 \mathrm{mg} / \mathrm{dl}$ was also significant $(\mathrm{r}=0.933, \mathrm{y}=1.112 \mathrm{x}+0.095$; $\mathrm{P}<0.0001$; Fig. 1B). Therefore, in accordance with a previous study (14), the results obtained with the STA analyzer were adjusted by applying an offset correction on the basis of the slope $(1 / 1.112=0.899)$ and the intercept $(-0.095 / 1.112=-0.086)$ obtained from samples with an $\mathrm{sCr}$ value of $<3.0 \mathrm{mg} / \mathrm{dl}$ was selected, as the correlation was stronger compared with the samples from $\mathrm{sCr}<2.0 \mathrm{mg} / \mathrm{dl}$.

Statistical analysis. The two sets of $\mathrm{sCr}$ and eGFR values obtained with the BM2250 and the STA analyzer were compared using the paired t-test. Linear regression scatter plots of $\mathrm{sCr}$ and eGFR values returned by STA and by BM2250 were constructed and assessed by Pearson's correlation coefficient. The association between the two datasets was evaluated by Bland-Altman plot analysis. The results of statistical analysis performed on samples assessed prior to and following STA adjustment were compared. The sensitivity, specificity, positive and negative predict value (PPV, NPV) and the accuracy for detecting patients at high-risk for CIN (eGFR $<45 \mathrm{ml} / \mathrm{min} / 1.73 \mathrm{~m}^{2}$ ) were calculated. For the statistical tests, Microsoft Office Excel 2010 for Windows was used (Microsoft Corporation, Redmond, WA, USA). P<0.05 was considered to indicate a statistically significant difference.

\section{Results}

Prior to adjustment, the mean $\mathrm{sCr}$ level was significantly lower when measured with the BM2250 compared with the STA 
A



B

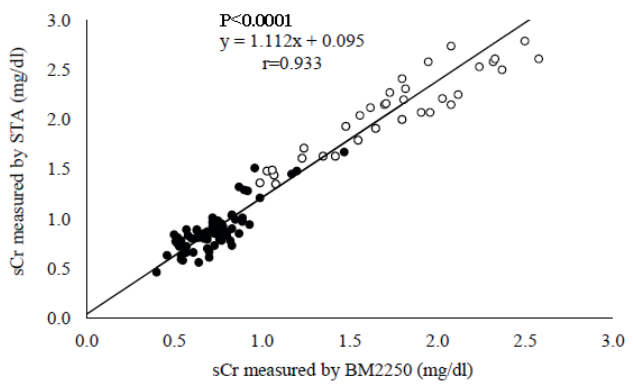

Figure 1. Scatter plots with linear regression in ranges of $\mathrm{sCr}(\mathrm{A})<2.0$ and $(\mathrm{B})<3.0 \mathrm{mg} / \mathrm{dl}$. Black dots, data from patient samples; white dots, data from volunteers; sCr, serum creatinine; STA, StatSensor-i; BM2250, BioMajesty ${ }^{\mathrm{TM}}$ automatic analyzer.

A

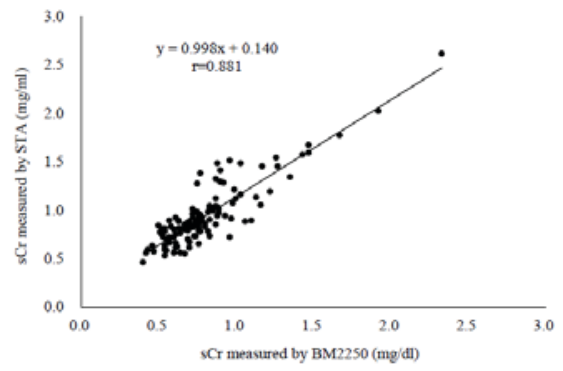

C

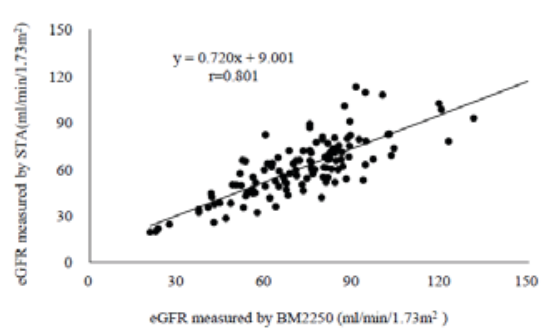

B

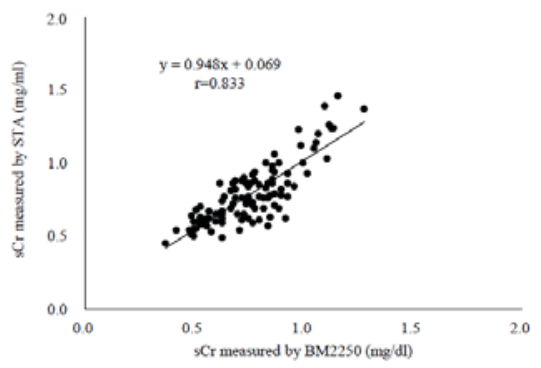

D

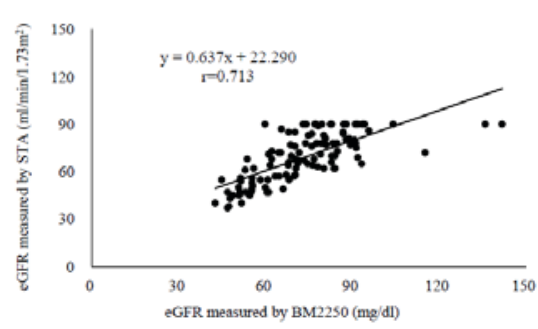

Figure 2. Linear regression scatter plots of sCr and eGFR measured with the STA and the BM2250 analyzer prior to and following adjustment. The sCr value (A) prior to $(\mathrm{r}=0.881, \mathrm{y}=0.998 \mathrm{x}+0.140)$ and $(\mathrm{B})$ following $(\mathrm{r}=0.833, \mathrm{y}=0.948+0.069)$ adjustment. The eGFR value $(\mathrm{C})$ prior to $(\mathrm{r}=0.801, \mathrm{y}=0.720 \mathrm{x}+9.001)$ and (D) following $(r=0.713, y=0.637 x+22.290)$ adjustment. All $\mathrm{P}<0.0001$. sCr, serum creatinine; eGFR, estimated glomerular filtration rate; STA, StatSensor-i; BM2250, BioMajesty ${ }^{\mathrm{TM}}$ automatic analyzer.

analyzer $(0.80 \pm 0.29$, range $0.75-2.33 \mathrm{mg} / \mathrm{dl}$ vs. $0.94 \pm 0.33$, range 0.46-2.61 mg/dl; P<0.0001; Table I). The mean eGFR calculated from the BM2250 data was higher than the mean eGFR obtained from STA data $\left(75.3 \pm 21.4\right.$, range $20.7-155.5 \mathrm{ml} / \mathrm{min} / 1.73 \mathrm{~m}^{2}$ vs. $61.6 \pm 19.2$, range $19.5-113.5 \mathrm{ml} / \mathrm{min} / 1.73 \mathrm{~m}^{2} ; \mathrm{P}<0.0001$; Table II). Following adjustment, the mean $\mathrm{sCr}$ measured with the BM2250 analyzer was significantly lower than the sCr obtained with the STA instrument $(0.76 \pm 0.18$, range $0.37-1.28 \mathrm{mg} / \mathrm{dl}$ vs. $0.79 \pm 0.21$, range $0.45-1.46 \mathrm{mg} / \mathrm{dl} ; \mathrm{P}<0.01$; Table II) and the mean eGFR was significantly higher when calculated with the BM2250, rather than STA data $(72.7 \pm 17.2$, range $42.7-142.0 \mathrm{ml} / \mathrm{min} / 1.73 \mathrm{~m}^{2}$ vs. $68.6 \pm 15.3$, range 37.0-90.0 ml/min $/ 1.73 \mathrm{~m}^{2}, \mathrm{P}<0.001$; Table II). Consequently, adjustment decreased the measurement error of $\mathrm{sCr}$ and eGFR measured with the BM2250 and the STA because the P-value increased following adjustment.

In the assessment of Pearson's correlation coefficient, there was a significant correlation between $\mathrm{sCr}$ values obtained with the STA and the BM2250 analyzer prior to $(r=0.881$, $\mathrm{y}=0.998 \mathrm{x}+0.140 ; \mathrm{P}<0.0001 ;$ Fig. $2 \mathrm{~A})$ and following adjustment $(\mathrm{r}=0.833, \mathrm{y}=0.948 \mathrm{x}+0.069 ; \mathrm{P}<0.0001$; Fig. 2B). These correlation coefficient revealed the adjustment improved the correlation $\mathrm{sCr}$ values obtained with the BM2250 and with the STA. There was a significant correlation between the eGFR measured prior to $(\mathrm{r}=0.801, \mathrm{y}=0.720 \mathrm{x}+9.001 ; \mathrm{P}<0.0001$; Fig. 2C) and following adjustment $(r=0.713, y=0.637 x+22.290$; $\mathrm{P}<0.0001$; Fig. 2D). The correlation coefficient of eGFR decreased in spite of improvements to the correlation $\mathrm{sCr}$ value following adjustment, as eGFR is affected by $\mathrm{sCr}$ and also sex and age. Based on the above results, the adjustment reduced the measurement error of $\mathrm{sCr}$ and eGFR and improved the $\mathrm{sCr}$ correlation values obtained with the BM2250 and the STA.

Pre-adjustment Bland-Altman plots revealed a difference in $\mathrm{sCr}$ levels of $>0.3 \mathrm{mg} / \mathrm{dl}$ in 13 of the 123 patient samples $(10.6 \%)$; the eGFR differed by $>15 \mathrm{ml} / \mathrm{min} / 1.73 \mathrm{~m}^{2}$ in 50 samples (40.7\%; Fig. 3A and B). Following the adjustment, there 
Table I. Differences in serum creatinine level between BM2250 and STA prior and following adjustment of STA.

\begin{tabular}{|c|c|c|c|}
\hline Variables & $\mathrm{BM} 2250$ & STA & P-value \\
\hline \multicolumn{4}{|l|}{ Prior to adjustment } \\
\hline Mean \pm SD (mg/dl) & $0.80 \pm 0.29$ & $0.94 \pm 0.33$ & $<0.0001$ \\
\hline Range (mg/dl) & $0.75-2.33$ & $0.87-2.61$ & \\
\hline \multicolumn{4}{|l|}{ Following adjustment } \\
\hline Mean \pm SD $(\mathrm{mg} / \mathrm{dl})$ & $0.76 \pm 0.18$ & $0.79 \pm 0.21$ & $<0.01$ \\
\hline Range (mg/dl) & $0.37-1.28$ & $0.45-1.46$ & \\
\hline
\end{tabular}

STA, StatSensor-i; BM2250, BioMajesty ${ }^{\mathrm{TM}}$ automatic analyzer; SD, standard deviation.

Table II. The difference of estimated glomerular filtration rate $\left(\mathrm{ml} / \mathrm{min} / 1.73 \mathrm{~m}^{2}\right)$ between BM2250 and STA prior and following adjustment of STA.

\begin{tabular}{lll}
\hline Variables & BM2250 & STA \\
\hline Prior to adjustment & & \\
Mean $\pm \mathrm{SD}\left(\mathrm{ml} / \mathrm{min} / 1.73 \mathrm{~m}^{2}\right)$ & $75.3 \pm 21.4$ & $61.6 \pm 19.2$ \\
Range $\left(\mathrm{ml} / \mathrm{min} / 1.73 \mathrm{~m}^{2}\right)$ & $20.7-155.5$ & $19.5-113.5$ \\
Following adjustment & & \\
Mean $\pm \mathrm{SD}\left(\mathrm{ml} / \mathrm{min} / 1.73 \mathrm{~m}^{2}\right)$ & $72.7 \pm 17.2$ & $68.6 \pm 15.3$ \\
Range $\left(\mathrm{ml} / \mathrm{min} / 1.73 \mathrm{~m}^{2}\right)$ & $42.7-142.0$ & $37.0-90.0$
\end{tabular}

STA, StatSensor-i; BM2250, BioMajesty ${ }^{\mathrm{TM}}$ automatic analyzer; SD, standard deviation.

A

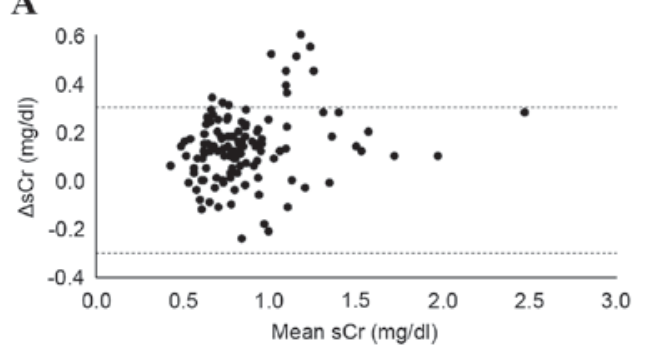

C

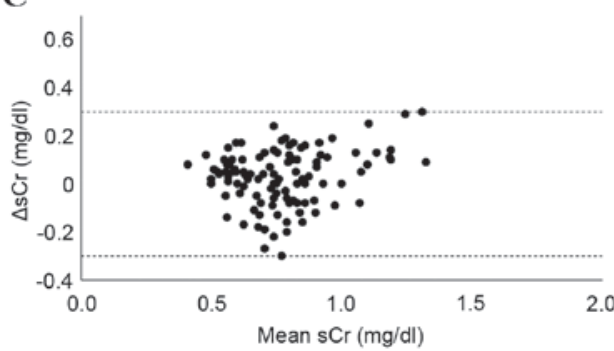

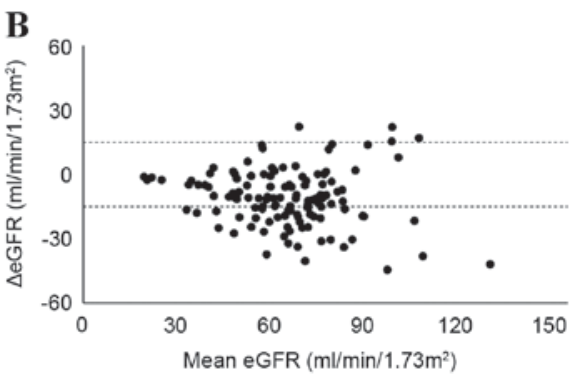

D



Figure 3. Bland-Altman plots of differences between sCr and eGFR values measured with the STA and the BM2250 analyzer prior to and following adjustment. The value of (A) sCr and (B) eGFR prior to adjustment. The value of (C) sCr and (D) eGFR following adjustment. $\Delta$ sCr=(creatinine value measured by STA)-(creatinine value measured by BM2250); $\Delta$ eGFR=(eGFR measured by STA)-(eGFR measured by BM2250); sCr; serum creatinine; eGFR, estimated glomerular filtration rate; STA, StatSensor-i; BM2250, BioMajesty ${ }^{\mathrm{TM}}$ automatic analyzer.

was no difference $>0.3 \mathrm{mg} / \mathrm{dl}$ in the $\mathrm{sCr}$ values. Differences exceeding $15 \mathrm{ml} / \mathrm{min} / 1.73 \mathrm{~m}^{2}$ in the eGFR were only detected among 17 of the 110 patient samples (15.5\%; Fig. 3C and D).
Of the 123 pre-adjustment samples, 24 (19.5\%) had an eGFR $<45 \mathrm{ml} / \mathrm{min} / 1.73 \mathrm{~m}^{2}$ according to the STA analyzer; 12 of 24 samples assessed with the BM2250 analyzer exhibited 
eGFR values of $\geq 45 \mathrm{ml} / \mathrm{min} / 1.73 \mathrm{~m}^{2}$. Therefore, the STA analyzer overdiagnosed 12 of the 123 unadjusted samples (9.8\%).

Following adjustment, 5 of 110 samples (4.5\%) exhibited eGFR $<45 \mathrm{ml} / \mathrm{min} / 1.73 \mathrm{~m}^{2}$; in 2 of 5 samples eGFR $\geq 45 \mathrm{ml} / \mathrm{min} / 1.73 \mathrm{~m}^{2}$. Consequently, 3 out of 110 samples $(2.7 \%)$ were overdiagnosed by the STA analyzer. The sensitivity, specificity, PPV, NPV and accuracy for the detection of patients at high risk for CIN (eGFR $\left.<45 \mathrm{ml} / \mathrm{min} / 1.73 \mathrm{~m}^{2}\right)$ were $100,89,50,100$ and $90.2 \%$ prior to and $100,96.3,33.3$, 100 and $96.4 \%$ following adjustment, respectively.

\section{Discussion}

According to the National Kidney Foundation, $\sim 13 \%$ of adults and $44 \%$ of individuals $>65$ years old have CKD, defined as a GFR $<60 \mathrm{ml} / \mathrm{min} / 1.73 \mathrm{~m}^{2}(16,17)$ and its incidence has markedly increased over the past 30 years $(18,19)$. Therefore, to avoid side effects such as CIN or NSF, a renal function test to measure GFR should be performed in patients with CKD, to determine the appropriateness of using contrast agents for imaging studies. The majority of institutions substitute the eGFR, calculated on the basis of the patient gender and age and sCr levels, for the GFR, as GFR is a more complex measurement for which $24 \mathrm{~h}$ urine collection is necessary. The European Society of Urogenital Radiology guidelines state that in high-risk patients, a GFR $<45 \mathrm{ml} / \mathrm{min} / 1.73 \mathrm{~m}^{2}$ and risk factors for CIN (such as dehydration, diabetic nephropathy, congestive heart failure, recent myocardial infarction, peri-procedural hypotension, low hematocrit level, age over 70 , concurrent administration of nephrotoxic drugs, and acute renal failure) justifies the transfusion of $0.9 \%$ saline or $1.26 \%$ sodium bicarbonate, a reduction in the contrast medium and measurement of the GFR 48-72 $\mathrm{h}$ following administration of iodine contrast agents (1). As a general rule, ICM should not be used in patients with a GFR $<30 \mathrm{ml} / \mathrm{min} / 1.73 \mathrm{~m}^{2}$ as the incidence of CIN is inversely proportional to the eGFR.

In patients scheduled for CT whose eGFR $>45 \mathrm{ml} / \mathrm{min} / 1.73 \mathrm{~m}^{2}$, a standard dose of ICM is typically administered. If their eGFR is between 45 and $30 \mathrm{ml} / \mathrm{min} / 1.73 \mathrm{~m}^{2}$, a reduced dose (70-80\%) of ICM is injected and a drip of $500 \mathrm{ml}$ saline is administered. When the eGFR is $<30 \mathrm{ml} / \mathrm{min} / 1.73 \mathrm{~m}^{2}$, an alternative modality is used, such as ultrasound, MRI or unenhanced CT studies. To determine whether it is necessary to reduce the dose of ICM and to stop the administration of ICN for the prevention of CIN, radiologists must ascertain whether the eGFR is $>45$, between 45 and 30 , or $<30 \mathrm{ml} / \mathrm{min} / 1.73 \mathrm{~m}^{2}$. Measurement errors around an eGFR between 30 and $45 \mathrm{ml} / \mathrm{min} / 1.73 \mathrm{~m}^{2}$ affect the $\mathrm{CT}$ protocol, that is, a reduction of ICM dose or alternative imaging methods are required (3). Therefore, as accuracy in this eGFR range (sCr range 1.0-2.5 mg/dl) is essential, the samples used for adjustment in the present study had to include the $\mathrm{sCr}$ (range $1.0-2.5 \mathrm{mg} / \mathrm{dl}$ ). However, strict accuracy may not be required in patients with $\mathrm{sCr}>3.0 \mathrm{mg} / \mathrm{dl}$ suggestive of high-grade CKD, as measurement errors in such patients tend not to affect the protocol used for CE-CT studies (3). Therefore, the current study did not use samples with an $\mathrm{sCr}$ value $>3.0 \mathrm{mg} / \mathrm{dl}$. As the correlation coefficient was improved in samples with a
$\mathrm{sCr}$ of $<3.0 \mathrm{mg} / \mathrm{dl}$, compared with a $\mathrm{sCr}$ of $<2.0 \mathrm{mg} / \mathrm{dl}$, the present study performed adjustment in samples with an $\mathrm{sCr}$ value $<3.0 \mathrm{mg} / \mathrm{dl}$.

Whereas $\mathrm{sCr}$ overestimation may lead to the decision to stop the administration of ICM for CT studies, its underestimation and the decision to administer the usual contrast dose may elicit CIN in patients with CKD. It has previously been reported that the STA analyzer was highly sensitive in determining whether renal function was normal or impaired and that without adjustment, it may underestimate sCr levels $(9,14)$. The present study demonstrates that it overestimates $\mathrm{sCr}$ with and without adjustment.

Prior to adjustment, the $\mathrm{sCr}$ value was $>0.3 \mathrm{mg} / \mathrm{dl}$ in $10.6 \%$ of the 123 patient samples; the measurement error for the eGFR exceeded $15 \mathrm{ml} / \mathrm{min} / 1.73 \mathrm{~m}^{2}$ in $40.7 \%$. Following adjustment, the error range in $\mathrm{sCr}$ measurements remained $<0.3 \mathrm{mg} / \mathrm{dl}$ and the measurement error for the eGFR fell from 40.7 to $15.5 \%$. Measurement errors of $>15 \mathrm{ml} / \mathrm{min} / 1.73 \mathrm{~m}^{2}$ were observed in patients with an eGFR $>60 \mathrm{ml} / \mathrm{min} / 1.73 \mathrm{~m}^{2}$. They did not lead to a change in the protocol for CE-CT in the current study.

Discrepancies between the STA and the BM2250 analyzer with respect to identifying samples with an eGFR $<45 \mathrm{ml} / \mathrm{min} / 1.73 \mathrm{~m}^{2}$ also decreased following adjustment. With the STA analyzer, 9.8\% of the samples were overdiagnosed prior to adjustment and $2.7 \%$ were overdiagnosed following adjustment. As adjustment increased the specificity and accuracy for the detection of patients at high risk of CIN (eGFR $<45 \mathrm{ml} / \mathrm{min} / 1.73 \mathrm{~m}^{2}$ ), the STA analyzer is useful for the evaluation of renal function in patients scheduled for CE-CT.

The current study had a number of limitations: 33/102 samples used for adjustment were obtained from healthy volunteers, as there were few patients with sCr levels $\geq 2.0 \mathrm{mg} / \mathrm{dl}$. Patient samples were drawn from a fingertip, whereas volunteer samples were collected from a vein for measurement by STA. This may have resulted in an improved correlation coefficient for samples with $\mathrm{sCr}$ value $<3.0 \mathrm{mg} / \mathrm{dl}$. The present study did not evaluate other laboratory values, although glucose interference $(\geq 200 \mathrm{mg} / \mathrm{dl})$ results in higher sCr levels (20) and red blood cell, plasma water fractions and hematocrit explain $91.8 \%$ of differences in $\mathrm{SCr}$ values obtained with the STA analyzer (21). Finally, the present study could not ascertain whether the eGFR was $<30 \mathrm{ml} / \mathrm{min} / 1.73 \mathrm{~m}^{2}$ both prior to and following adjustment, as few samples were available from patients with an eGFR $<30 \mathrm{ml} / \mathrm{min} / 1.73 \mathrm{~m}^{2}$.

In conclusion, appropriate adjustment reduced measurement errors in values obtained with the STA analyzer. Adjustment of the STA instrument is essential for the evaluation of renal function prior to administration of contrast media. The point-of-care creatinine analyzer (STA) may alert individuals to the danger of CIN in high-risk patients.

\section{Acknowledgements}

The authors of the present study would like to thank Ryoji Hiwatashi (Nova Biomedical, Tokyo, Japan), Yukio Imura (Kyorin Systemac, Kawaguchi, Japan), and Kozo Okui (Kohka Public Hospital, Minakuchi, Japan) for adjustment of STA in the laboratory and Akiko Kawashima (Kohka Public Hospital) 
for collecting blood samples and Ursula A. for the English language review.

\section{References}

1. Stacul F, van der Molen AJ, Reimer P, Webb JA, Thomsen HS Morcos SK, Almén T, Aspelin P, Bellin MF, Clement O, et al: Contrast induced nephropathy: Updated ESUR contrast media safety committee guidelines. Eur Radiol 21: 2527-2541, 2011.

2. Thomsen HS, Morcos SK, Almén T, Bellin MF, Bertolotto M, Bongartz G, Clement O, Leander P, Heinz-Peer G, Reimer P, et al: Nephrogenic systemic fibrosis and gadolinium-based contrast media: Updated ESUR Contrast Medium Safety Committee guidelines. Eur Radiol 23: 307-318, 2013.

3. Tao SM, Wichmann JL, Schoepf UJ, Fuller SR, Lu GM and Zhang LJ: Contrast-induced nephropathy in CT: Incidence, risk factors and strategies for prevention. Eur Radiol 26: 3310-3318, 2016.

4. Seabra VF, Balk EM, Liangos O, Sosa MA, Cendoroglo M and Jaber BL: Timing of renal replacement therapy initiation in acute renal failure: A meta-analysis. Am J Kidney Dis 52: 272-284, 2008.

5. Bennett CL, Qureshi ZP, Sartor AO, Norris LB, Murday A, Xirasagar S and Thomsen HS: Gadolinium-induced nephrogenic systemic fibrosis: The rise and fall of an iatrogenic disease. Clin Kidney J 5: 82-88, 2012.

6. Marckmann P and Skov L: Nephrogenic systemic fibrosis: Clinical picture and treatment. Radiol Clin North Am 47: 833-840, 2009

7. Sadat U: Radiographic contrast-media-induced acute kidney injury: Pathophysiology and prophylactic strategies. ISRN Radiol 16: 496438, 2013.

8. Kuhn MJ, Chen N, Sahani DV, Reimer D, van Beek EJ, Heiken JP and So GJ: The PREDICT study: A randomized double-blind comparison of contrast-induced nephropathy after low- or isoosmolar contrast agent exposure. AJR Am J Roentgenol 191: $151-157,2008$

9. Shephard M, Peake M, Corso O, Shephard A, Mazzachi B, Spaeth B, Barbara J and Mathew T: Assessment of the Nova StatSensor whole blood point-of-care creatinine analyzer for the measurement of kidney function in screening for chronic kidney disease. Clin Chem Lab Med 48: 1113-1119, 2010.

10. Kosack CS, de Kieviet W, Bayrak K, Milovic A and Page AL: Evaluation of the Nova StatSensor ${ }^{\circledR}$ Xpress (TM) Creatinine point-of-care handheld analyzer. PLoS One 10: e0122433, 2015 .
11. van Lint CL, van der Boog PJ, Romijn FP, Schenk PW, van Dijk S, Rövekamp TJ, Kessler A, Siekmann L, Rabelink TJ and Cobbaert CM: Application of a point of care creatinine device for trend monitoring in kidney transplant patients: Fit for purpose? Clin Chem Lab Med 53: 1547-1556, 2015.

12. Korpi-Steiner NL, Williamson EE and Karon BS: Comparison of three whole blood creatinine methods for estimation of glomerular filtration rate before radiographic contrast administration. Am J Clin Pathol 132: 920-926, 2009.

13. Morita S, Suzuki K, Masukawa A and Ueno E: Assessing renal function with a rapid, handy, point-of-care whole blood creatinine meter before using contrast materials. Jpn J Radiol 29: 187-193, 2011.

14. Haneder S, Gutfleisch A, Meier C, Brade J, Hannak D, Schoenberg SO, Becker CR and Michaely HJ: Evaluation of a handheld creatinine measurement device for real-time determination of serum creatinine in radiology departments. World $\mathrm{J}$ Radiol 4: 328-334, 2012.

15. Imai E, Horio M, Nitta K, Yamagata K, Iseki K, Hara S, Ura N, Kiyohara Y, Hirakata H, Watanabe T, et al: Estimation of glomerular filtration rate by the MDRD study equation modified for Japanese patients with chronic kidney disease. Clin Exp Nephrol 11: 41-50, 2007.

16. Rivera JA, O'Hare AM and Harper GM: Update on the management of chronic kidney disease. Am Fam Physician 86: 749-754, 2012.

17. Stevens LA, Li S, Wang C, Huang C, Becker BN, Bomback AS, Brown WW, Burrows NR, Jurkovitz CT, McFarlane SI, et al: Prevalence of CKD and comorbid illness in elderly patients in the United States: Results from the Kidney Early Evaluation Program (KEEP). Am J Kidney Dis 55 (3 Suppl 2): S23-S33, 2010.

18. Nagata M, Ninomiya T, Doi Y, Yonemoto K, Kubo M, Hata J, Tsuruya K, Iida M and Kiyohara Y: Trends in the prevalence of chronic kidney disease and its risk factors in a general Japanese population: The hisayama study. Nephrol Dial Transplant 25: 2557-2564, 2010.

19. Coresh J, Selvin E, Stevens LA, Manzi J, Kusek JW, Eggers P, Van Lente F and Levey AS: Prevalence of chronic kidney disease in the United states. JAMA 298: 2038-2047, 2007.

20. Srihong C, Pangsapa K, Chuaboonmee K, Kotipan Y and Charuruks N: Evaluation of the analytical performance of the nova StatSensor creatinine meter for blood testing. J Med Assoc Thai 95: 1225-1231, 2012

21. Straseski JA, Lyon ME, Clarke W, Dubois JA, Phelan LA and Lyon AW: Investigating interferences of a whole-blood point-of-care creatinine analyzer: Comparison to plasma enzymatic and definitive creatinine methods in an acute-care setting. Clin Chem 57: 1566-1573, 2011. 